\title{
Surgical versus nonsurgical treatment in first traumatic anterior dislocation of the shoulder in athletes
}

This article was published in the following Dove Press journal:

Open Access Journal of Sports Medicine

I4 March 201।

Number of times this article has been viewed

\section{Gustavo Gonçalves Arliani \\ Diego da Costa Astur \\ Carina Cohen \\ Benno Ejnisman \\ Carlos Vicente Andreoli \\ Alberto Castro Pochini \\ Moises Cohen}

Centro de Traumatologia do Esporte (CETE), Departamento de Ortopedia e Traumatologia da Universidade Federal de São Paulo, São Paulo, Brazil
Abstract: Anterior traumatic dislocation is a common problem faced by orthopedic surgeons. After the first episode of shoulder dislocation, a combination of lesions can lead to chronic instability. The management in treatment of young athletes after the first acute anterior shoulder dislocation is controversial. The available literature supports early surgical treatment for young male athletes engaged in highly demanding physical activities after the first episode of traumatic dislocation of the shoulder. This is because of the best functional results and lower recurrence rates obtained with this treatment in this population. However, further clinical trials of good quality comparing surgical versus nonsurgical treatment for well-defined lesions are needed, especially for categories of patients who have a lower risk of recurrence.

Keywords: athlete, conservative treatment, surgical treatment, immobilization, stabilization, primary treatment, shoulder dislocation

\section{Introduction}

The shoulder has the greatest joint range of motion of the human body. As a result, this articulation is particularly susceptible to dislocation and subluxation events. This is because stability has been sacrificed to achieve a wide range of motion. ${ }^{1}$

The functional stability of the glenohumeral joint is achieved through static and dynamic stabilizers. ${ }^{2,3}$

The static stabilizers include the negative intraarticular pressure, size, shape and orientation of the glenoid fossa, and the stabilizing presence of the capsulolabral complex. The dynamic stabilizers include the rotator cuff's muscles and the long head of biceps tendon., ${ }^{2,3}$

Dislocations occur more frequently when the arm is forced in a position of abduction and maximal external rotation as a result of an anterior leverage of the humeral head to a position out of the joint. ${ }^{4-6}$

After the first episode of shoulder dislocation, a combination of lesions can lead to chronic instability, particularly injuries involving the inferior glenohumeral ligament, which is the most important passive stabilizer of the shoulder. ${ }^{3}$

Anterior traumatic dislocation is a common problem faced by orthopedic surgeons.

This joint is the most common articulation involved in episodes of dislocation, showing a rate of $11.2 / 100,000$ per year and an estimated prevalence of $2 \%$ in the general population..$^{7-10}$

The main cause of primary shoulder dislocation is traumatic as almost $95 \%$ of the first episodes of dislocation are derived from a strong collision, landing on an
Correspondence: Gustavo Gonçalves Arliani Centro de Traumatologia do Esporte (CETE), Departamento de Ortopedia e Traumatologia da Universidade Federal de São Paulo, São Paulo, Brazil

Tel +55 | | 557| 662 I

Fax +55 II 55794642

Email ggarliani@hotmail.com 
outstretched arm, or by a sudden and violent motion of the shoulder. ${ }^{6}$

Rowe has identified a bimodal distribution, with peaks of shoulder dislocations in the second and sixth decades of life. ${ }^{6,11}$

As a result, young and old people have a comparable incidence of shoulder primary dislocation. However, the incidence of recurrent dislocation is highly dependent on age and occurs more often in the adolescent population.

Recurrent dislocation was reported in $66 \%-100 \%$ of people aged 20 years or less, $13 \%-63 \%$ of people aged between 20 and 40 years, and $0 \%-16 \%$ of people over 40 years. ${ }^{11-15}$

The high incidence of recurrent dislocation of the shoulder during adolescence can be explained in part by the profile of existing collagen presented in the capsule and other tissues of the shoulder in this population. The greatest amount of elastic collagen (type 3 ) in tendons and ligaments may help explain the greater propensity of younger patients to recurrent dislocation of the shoulder compared with older patients. ${ }^{6}$

The management in treatment of young athletes after the first acute anterior shoulder dislocation is controversial. ${ }^{16,17}$

Although these lesions have traditionally been treated conservatively with immobilization followed by a rehabilitation program, recurrent rates that reached $100 \%$ in skeletally immature patients and $96 \%$ in adolescents have been observed in some studies. ${ }^{1,16,17}$

Recently, randomized clinical trials showed lower rates of recurrent instability and better results in young patients treated with surgical stabilization. ${ }^{1,18-20}$

The aim of this article is to review the data published about the management of athletes after the first episode of traumatic anterior shoulder dislocation.

\section{Nonsurgical treatment}

Several methods of treatment, such as immobilization, activity restriction, and physical therapy rehabilitation, appear as options in the nonoperative treatment after the first traumatic anterior dislocation. ${ }^{6}$

Regarding the positioning of the upper limb during the immobilization period, studies in cadavers and in patients using magnetic resonance imaging and arthroscopy showed a closer relationship between the Bankart lesion and glenoid with the humerus positioned in adduction and external rotation. $^{21-26}$

Itoi et al recently presented the results of a prospective trial, comparing immobilization of the shoulder in internal rotation versus $10^{\circ}$ of external rotation for 3 weeks. The authors found that immobilization in external rotation significantly reduces the risk of recurrence compared with the conventional method of immobilization. ${ }^{27}$

Another prospective study, however, showed that immobilization in external rotation may not be as effective as previously reported in the prevention of recurrent dislocation of the shoulder. ${ }^{28}$

Although some studies advocate a conservative treatment with immobilization in external rotation, a study showed that this was not well tolerated by patients during the treatment period..$^{29}$ Moreover, another study showed that immobilization of the upper limb with a brace in a position of external rotation is well accepted by most patients. ${ }^{30}$

Nonsurgical treatment with immobilization of the limb in external rotation is not well accepted by orthopedic surgeons too. In a recent study in the UK, $93 \%$ of respondents supported the immobilization in internal rotation in nonoperative treatment after first shoulder dislocation. ${ }^{31}$

A systematic review on the subject concluded that there is lack of evidence from randomized trials to inform choices of nonsurgical treatment after closed reduction of traumatic anterior dislocation of the shoulder. In this study, no statistically significant difference was observed between the postreduction immobilization with the arm in external or internal rotation when assessing the level of return to sports and the incidence of posttraumatic instability of the shoulder. $^{32}$

The duration of immobilization after a traumatic dislocation of the shoulder is also controversial. Most authors concluded that this does not influence the recurrence rates. ${ }^{12,33-36}$ Hovelius et al, in a prospective study with 257 patients, found no differences in recurrence rates between treatment with early mobilization and immobilization of the shoulder by a period of 3-4 weeks. ${ }^{12}$ Other retrospective studies found no beneficial effect on results with immobilization for a period exceeding 6 weeks. ${ }^{13,37}$ A study with 116 patients reported an overall recurrence rate of $33 \%$, with no difference in recurrence due to the immobilization period between 0 and 6 weeks. ${ }^{37}$ In the same study, $82 \%$ of athletes suffered a new episode of dislocation while only $30 \%$ of nonathletes of similar age had relapsed. Although the duration of immobilization did not influence the recurrence rate, significantly better results were reported by patients with $6-8$ weeks of restricted activity compared to rest duration of $<6$ weeks. ${ }^{6}$

Other authors found that lack of restraint had a negative effect on the recurrence rate compared with a period of 3 weeks of immobilization. ${ }^{38}$ Likewise, Kiviluoto et al found a difference in the rate of redislocation, according 
to the length of treatment, with a period of 3 weeks of immobilization showing lower rates of recurrence compared with only 1 week of immobilization. ${ }^{39}$ Maeda et al noted that in rugby players, the period between the first and second episodes of dislocation was higher when the shoulder was immobilized for 4 weeks or more compared to another similar group immobilized for $<3$ weeks. ${ }^{40}$

There are few studies presenting the results of nonsurgical treatment based on physical therapy rehabilitation. ${ }^{6}$ In a prospective study with 20 male patients (age range 18-22 years), Aronen and Regan reported an unrestricted return to sports in $75 \%$ of cases with a rehabilitation program that emphasized strengthening of the adductor and internal rotator muscles of the shoulder. ${ }^{41}$ Another study with 104 patients reported a success rate of $83 \%$ with nonoperative treatment with a limited abduction 6-week exercise regimen.

These studies support the restriction of activity and rehabilitation in nonsurgical treatment after first traumatic anterior dislocation. However, scientific studies are needed to clarify the effectiveness of physiotherapy in treatment of this entity. ${ }^{6}$

\section{Surgical treatment}

The most recent and successful surgical procedure for unidirectional shoulder instability treatment has the aim to restore the anatomic position of the labrum and glenohumeral ligaments associated with little damage to other structures of the shoulder (Bankart repair). ${ }^{6}$

This surgical procedure can be performed through open stabilization or, more recently, by arthroscopy. The advent of arthroscopy and advance in equipment and techniques have made this technique the most commonly used procedure nowadays. ${ }^{7,42,43}$ This procedure has been described using a variety of fixation techniques, including transglenoid sutures, staples, and bioabsorbable anchors. ${ }^{744}{ }^{77}$ The anchors have recently become the preferred method of fixation, as it allows a more anatomical positioning of the labrum around the glenoid rim through a secure grip. ${ }^{42,43} \mathrm{~A}$ recent study comparing transglenoid sutures and suture anchors concluded that suture anchors are better, leading to significantly lower rates of recurrence. ${ }^{48}$ One study showed that the type of suture used, absorbable or nonabsorbable, did not influence the functional outcome of arthroscopic treatment of traumatic anterior shoulder instability. ${ }^{49}$

Some authors recommend open stabilization instead of arthroscopic treatment for young, high-level athletes as a way to guarantee a low recurrence rate in those individuals subjected to high training loads. ${ }^{50-52}$
Although Bankart repair is the procedure that is often performed in the treatment of glenohumeral instability, a clinical trial, with a follow-up period of 2 years, which compared arthroscopic lavage and conventional nonsurgical treatment, showed that this surgical procedure reduced the risk of recurrence after the first episode of traumatic dislocation of the shoulder. ${ }^{53}$

\section{Comparison between surgical and nonsurgical treatments}

The management after the first traumatic anterior glenohumeral dislocation in athletes is controversial. According to several authors who advocate surgical treatment, most patients who sustain a traumatic anterior shoulder dislocation have an avulsion injury of the anterior labrum at surgery. ${ }^{20,54}$ And since the capsulolabral complex is the greater anterior passive stabilizer of the shoulder, the high recurrence rate observed with the use of nonoperative treatment could be attributed to a failure of the labrum to heal in an anatomic position. On the other hand, the arthroscopic repair can directly address these structures, as opposed to nonsurgical treatment. ${ }^{20}$

Proponents of surgical treatment after the first episode of dislocation also argue that the chances of recurrence are high and therefore surgery should be performed before its occurrence. ${ }^{10}$ Some authors, however, argue that surgical treatment is demanding, and recurrence and other complications, such as stiffness and pain after surgery, are still present. ${ }^{18,21,27,39}$ Besides these factors, a study showed that surgical treatment can restore the function and stability of the shoulder to near normal values; however, there is a significant impairment of quality of life and performance in sports activities during a period of 2 years after surgery, including decreased activity and muscle strength. ${ }^{55}$ Other authors argue that not all cases of recurrent dislocation of the shoulder will require surgery, since some patients are able to handle the problem without a significant reduction in their level and type of activities.

No studies have demonstrated that the surgery performed after a primary dislocation has better results than that performed after a recurrence. Epidemiological data indicate that applying a policy of primary surgery in these cases may lead to a significant number of unnecessary surgeries. ${ }^{14,15}$ In the study of West Point, $20 \%$ of surgeries after an initial traumatic dislocation, even among athletes, would be unnecessary, and an additional $14 \%$ of surgeries were unsuccessful. ${ }^{56,57}$

Younger patients and practitioners of high-impact sports are more prone to further episodes of dislocation after an 
Table I Randomized clinical trials' results

\begin{tabular}{|c|c|c|c|c|c|c|c|}
\hline & n (gender) & Age (years) & Population & $\begin{array}{l}\text { Surgical } \\
\text { approach }\end{array}$ & $\begin{array}{l}\% \text { nonsurgical } \\
\text { recurrence rate }\end{array}$ & $\begin{array}{l}\% \text { surgical } \\
\text { recurrence rate }\end{array}$ & $\begin{array}{l}\text { Follow } \\
\text { up (months) }\end{array}$ \\
\hline $\begin{array}{l}\text { Bottoni } \\
2002\end{array}$ & $\begin{array}{l}24 \\
\text { (all male) }\end{array}$ & $\begin{array}{l}\text { I8-26 } \\
\text { (average } 22.4 \text { y) }\end{array}$ & $\begin{array}{l}\text { All military personnel } \\
\text { and their families }\end{array}$ & Arthroscopic & 75 & I I,I & $\begin{array}{l}16-56 \\
\text { (average } 36 \mathrm{~m} \text { ) }\end{array}$ \\
\hline $\begin{array}{l}\text { Kirkley } \\
2005\end{array}$ & $\begin{array}{l}40 \\
(35 \mathrm{M} \text { and } 5 \mathrm{~F})\end{array}$ & $\begin{array}{l}<30 \\
\text { (average } 22.4 \text { y) }\end{array}$ & $\begin{array}{l}\text { Patients of } 2 \text { ED } \\
\text { university centres }\end{array}$ & Arthroscopic & 47 & 15,9 & $\begin{array}{l}5 \mathrm{I}-102 \\
\text { (average } 79 \mathrm{~m} \text { ) }\end{array}$ \\
\hline \multirow[t]{2}{*}{2007} & $\begin{array}{l}76 \\
(62 \mathrm{M} \text { and } \mathrm{I} 4 \mathrm{~F})\end{array}$ & $\begin{array}{l}\text { I5-39 } \\
\text { (average 21.5 y) }\end{array}$ & $\begin{array}{l}\text { Patients of I } 3 \text { ED } \\
\text { hospitals }\end{array}$ & Open & 54 & 3 & 24 \\
\hline & & & & & 62 & 9 & 120 \\
\hline
\end{tabular}

Abbreviations: M, male; F, female; ED, emergency department.

initial event. However, only about $50 \%$ of these will require surgery. And when this is performed after the first acute dislocation, based on the presumption of future dislocations, unhappiness, and disability, cannot be justified. ${ }^{58}$ Thus, it would be helpful to use specific tools to predict the risk of recurrence after the first traumatic dislocation of the shoulder. With these tools, patients at high risk of redislocation could be identified and submitted to a primary surgery, thus reducing the risk of recurrence.

One study showed that the anterior apprehension test carried out between 6 and 9 weeks after dislocation is not an ultimate weapon to predict the risk of recurrence. However, it is an important tool to categorize patients as high or low risk for recurrence.$^{57}$ Moreover, the presence of greater tuberosity fractures and fractures of the glenoid rim is considered as a good predictor of stability and function of the shoulder after a traumatic dislocation of the shoulder. ${ }^{59}$

Another important factor when choosing a treatment method is the fact that patients with anterior shoulder instability have a significantly higher prevalence of injury of the anterior inferior labrum and bone lesions compared with patients after the first episode of dislocation. ${ }^{60}$

In an attempt to determine the best treatment option after the first episode of traumatic dislocation of the shoulder, few randomized clinical trials were conducted. ${ }^{8,18,61}$ The results are shown in Table 1.

These studies showed better functional outcomes for patients undergoing surgical treatment and showed no difference in shoulder's range of motion between the two groups of patients.

A systematic review concluded that there is limited available evidence supporting primary surgery for young adults and athletes, usually male, engaged in highly demanding physical activities after the first traumatic dislocation. However, there is no evidence available to determine whether nonsurgical treatment should not remain the main treatment option for other categories of patients. Therefore, further clinical trials of good quality comparing surgical versus nonsurgical treatment for well-defined lesions are needed, especially for categories of patients who have a lower risk of recurrence. ${ }^{19}$

\section{Discussion}

Since available data comparing the options of surgical and nonsurgical treatment are limited, the need for more studies of quality is evident, especially studies comparing surgical versus nonoperative treatment for injuries involving the well-defined categories of patients who have a lower risk of recurrence.

The available literature supports early surgical treatment for young male athletes engaged in highly demanding physical activities after the first episode of traumatic dislocation of the shoulder. This is because of the best functional results and lower recurrence rates obtained with this treatment in this population. However, we believe that the patient's sport, physical examination, age, gender, the period of the season in which the injury occurred, extent of shoulder structure injury, and the expectations of the athlete in relation to surgery are important factors in choosing a specific method of treatment and should be discussed with the patient.

\section{Disclosure}

The authors report no conflicts of interest in this work.

\section{References}

1. Good CR, MacGillivray JD. Traumatic shoulder dislocation in the adolescent athlete: advances in surgical treatment. Curr Opin Pediatr. 2005;17(1):25-29.

2. Chant CB, Litchfield R, Griffin S, Thain LM. Humeral head retroversion in competitive baseball players and its relationship to glenohumeral rotation range of motion. J Orthop Sports Phys Ther. 2007;37(9): 514-520.

3. Bergin D. Imaging shoulder instability in the athlete. Magn Reson Imaging Clin NAm. 2009;17(4):595-615, v.

4. Aronen JG. Anterior shoulder dislocations in sports. Sports Med. 1986; 3(3):224-234.

5. Liu SH, Henry MH. Anterior shoulder instability. Current review. Clin Orthop. 1996;(323):327-337. 
6. Hayes K, Callanan M, Walton J, Paxinos A, Murrell GA. Shoulder instability: management and rehabilitation. J Orthop Sports Phys Ther. 2002;32(10):497-509.

7. Brophy RH, Marx RG. The treatment of traumatic anterior instability of the shoulder: nonoperative and surgical treatment. Arthroscopy. 2009; 25(3):298-304.

8. Kirkley A, Werstine R, Ratjek A, Griffin S. Prospective randomized clinical trial comparing the effectiveness of immediate arthroscopic stabilization versus immobilization and rehabilitation in first traumatic anterior dislocations of the shoulder: long-term evaluation. Arthroscopy. 2005;21(1):55-63.

9. Kirkley A, Griffin S, McLintock H, Ng L. The development and evaluation of a disease-specific quality of life measurement tool for shoulder instability. The Western Ontario Shoulder Instability Index (WOSI). Am J Sports Med. 1998;26(6):764-772.

10. Simonet WT, Melton LJ 3rd, Cofield RH, Ilstrup DM. Incidence of anterior shoulder dislocation in Olmsted County, Minnesota. Clin Orthop Relat Res. 1984;(186):186-191.

11. Rowe CR. Prognosis in dislocations of the shoulder. J Bone Joint Surg Am. 1956;38-A(5):957-977.

12. Hovelius L, Eriksson K, Fredin H, et al. Recurrences after initial dislocation of the shoulder. Results of a prospective study of treatment. J Bone Joint Surg Am. 1983;65(3):343-349.

13. Marans HJ, Angel KR, Schemitsch EH, Wedge JH. The fate of traumatic anterior dislocation of the shoulder in children. J Bone Joint Surg Am. 1992;74(8):1242-1244.

14. McLaughlin HL, Cavallaro WU. Primary anterior dislocation of the shoulder. Am J Surg. 1950;80(6):615-621; passim.

15. Rowe CR, Zarins B. Recurrent transient subluxation of the shoulder. J Bone Joint Surg Am. 1981;63(6):863-872.

16. Owens BD, DeBerardino TM, Nelson BJ, et al. Long-term follow-up of acute arthroscopic Bankart repair for initial anterior shoulder dislocations in young athletes. Am J Sports Med. 2009;37(4): 669-673.

17. Wheeler JH, Ryan JB, Arciero RA, Molinari RN. Arthroscopic versus nonoperative treatment of acute shoulder dislocations in young athletes. Arthroscopy. 1989;5(3):213-217.

18. Bottoni CR, Wilckens JH, DeBerardino TM, et al. A prospective, randomized evaluation of arthroscopic stabilization versus nonoperative treatment in patients with acute, traumatic, first-time shoulder dislocations. Am J Sports Med. 2002;30(4):576-580.

19. Handoll HH, Almaiyah MA, Rangan A. Surgical versus non-surgical treatment for acute anterior shoulder dislocation. Cochrane Database Syst Rev. 2004;1:CD004325

20. Kirkley A, Griffin S, Richards C, Miniaci A, Mohtadi N. Prospective randomized clinical trial comparing the effectiveness of immediate arthroscopic stabilization versus immobilization and rehabilitation in first traumatic anterior dislocations of the shoulder. Arthroscopy. 1999; 15(5):507-514.

21. De Baere T, Delloye C. First-time traumatic anterior dislocation of the shoulder in young adults: the position of the arm during immobilisation revisited. Acta Orthop Belg. 2005;71(5):516-520.

22. Seybold D, Gekle C, Fehmer T, Pennekamp W, Muhr G, Kalicke T. Immobilization in external rotation after primary shoulder dislocation. Chirurg. 2006;77(9):821-826.

23. Scheibel M, Kuke A, Nikulka C, Magosch P, Ziesler O, Schroeder RJ. How long should acute anterior dislocations of the shoulder be immobilized in external rotation? Am J Sports Med. 2009;37(7):1309-1316.

24. Miller BS, Sonnabend DH, Hatrick C, et al. Should acute anterior dislocations of the shoulder be immobilized in external rotation? A cadaveric study. J Shoulder Elbow Surg. 2004;13(6):589-592.

25. Hart WJ, Kelly CP. Arthroscopic observation of capsulolabral reduction after shoulder dislocation. J Shoulder Elbow Surg. 2005; 14(2):134-137.

26. Liavaag S, Stiris MG, Lindland ES, Enger M, Svenningsen S, Brox JI. Do Bankart lesions heal better in shoulders immobilized in external rotation? Acta Orthop. 2009;80(5):579-584.
27. Itoi E, Hatakeyama Y, Sato T, et al. Immobilization in external rotation after shoulder dislocation reduces the risk of recurrence. A randomized controlled trial. J Bone Joint Surg Am . 2007;89(10):2124-2131.

28. Finestone A, Milgrom C, Radeva-Petrova DR, et al. Bracing in external rotation for traumatic anterior dislocation of the shoulder. J Bone Joint Surg Br. 2009;91(7):918-921.

29. Itoi E, Hatakeyama Y, Kido T, et al. A new method of immobilization after traumatic anterior dislocation of the shoulder: a preliminary study. J Shoulder Elbow Surg. 2003;12(5):413-415.

30. Schliemann B, Seybold D, Muhr G, Gekle C. Immobilisation of the shoulder in external rotation after traumatic first-time dislocation-what is reasonable? A retrospective survey. Sportverletz Sportschaden. 2009; 23(2):100-105.

31. Chong M, Karataglis D, Learmonth D. Survey of the management of acute traumatic first-time anterior shoulder dislocation among trauma clinicians in the UK. Ann R Coll Surg Engl. 2006;88(5):454-458.

32. Handoll HH, Hanchard NC, Goodchild L, Feary J. Conservative management following closed reduction of traumatic anterior dislocation of the shoulder. Cochrane Database Syst Rev. 2006;(1):CD004962.

33. Henry JH, Genung JA. Natural history of glenohumeral dislocationrevisited. Am J Sports Med. 1982;10(3):135-137.

34. Hovelius L, Augustini BG, Fredin H, Johansson O, Norlin R, Thorling J. Primary anterior dislocation of the shoulder in young patients. A ten-year prospective study. J Bone Joint Surg Am. 1996;78(11):1677-1684.

35. Lill H, Verheyden P, Korner J, Hepp P, Josten C. Conservative treatment after first traumatic shoulder dislocation. Chirurg. 1998;69(11):1230-1237.

36. Ryf C, Matter P. The initial traumatic shoulder dislocation. Prospective study. Z Unfallchir Versicherungsmed. 1993;Suppl 1:204-212.

37. Simonet WT, Cofield RH. Prognosis in anterior shoulder dislocation. Am J Sports Med. 1984;12(1):19-24.

38. Rowe CR, Sakellarides HT. Factors related to recurrences of anterior dislocations of the shoulder. Clin Orthop. 1961;20:40-48.

39. Kiviluoto O, Pasila M, Jaroma H, Sundholm A. Immobilization after primary dislocation of the shoulder. Acta Orthop Scand. 1980;51(6): 915-919.

40. Maeda A, Yoneda M, Horibe S, Hirooka A, Wakitani S, Narita Y. Longer immobilization extends the "symptom-free" period following primary shoulder dislocation in young rugby players. J Orthop Sci. 2002;7(1):43-47.

41. Aronen JG, Regan K. Decreasing the incidence of recurrence of first time anterior shoulder dislocations with rehabilitation. Am J Sports Med. 1984;12(4):283-291.

42. Armstrong A, Boyer D, Ditsios K, Yamaguchi K. Arthroscopic versus open treatment of anterior shoulder instability. Instr Course Lect. 2004; 53:559-563.

43. Cole BJ, Millett PJ, Romeo AA, et al. Arthroscopic treatment of anterior glenohumeral instability: indications and techniques. Instr Course Lect. 2004;53:545-558.

44. Mologne TS, Lapoint JM, Morin WD, Zilberfarb J, O’Brien TJ. Arthroscopic anterior labral reconstruction using a transglenoid suture technique. Results in active-duty military patients. Am J Sports Med. 1996;24(3):268-274.

45. Detrisac DA, Johnson LL. Arthroscopic shoulder capsulorrhaphy using metal staples. Orthop Clin North Am. 1993;24(1):71-88.

46. Speer KP, Warren RF, Pagnani M, Warner JJ. An arthroscopic technique for anterior stabilization of the shoulder with a bioabsorbable tack. J Bone Joint Surg Am. 1996;78(12):1801-1807.

47. Warner JJ, Miller MD, Marks P, Fu FH. Arthroscopic Bankart repair with the Suretac device. Part I: Clinical observations. Arthroscopy. 1995;11(1):2-13.

48. Van Oostveen DP, Schild FJ, van Haeff MJ, Saris DB. Suture anchors are superior to transglenoid sutures in arthroscopic shoulder stabilization. Arthroscopy. 2006;22(12):1290-1297.

49. Monteiro GC, Ejnisman B, Andreoli CV, Pochini AC, Cohen M. Absorbable versus nonabsorbable sutures for the arthroscopic treatment of anterior shoulder instability in athletes: a prospective randomized study. Arthroscopy. 2008;24(6):697-703. 
50. Pagnani MJ, Dome DC. Surgical treatment of traumatic anterior shoulder instability in american football players. J Bone Joint Surg Am. 2002;84-A(5):711-715.

51. Ambacher T, Paar O. Traumatic shoulder dislocation in young athletesopen or arthroscopic stabilization?. Sportverletz Sportschaden. 1999; 13(3):68-73.

52. Roberts SN, Taylor DE, Brown JN, Hayes MG, Saies A. Open and arthroscopic techniques for the treatment of traumatic anterior shoulder instability in Australian rules football players. J Shoulder Elbow Surg. 1999;8(5):403-409.

53. Wintzell G, Haglund-Akerlind Y, Nowak J, Larsson S. Arthroscopic lavage compared with nonoperative treatment for traumatic primary anterior shoulder dislocation: a 2-year follow-up of a prospective randomized study. J Shoulder Elbow Surg. 1999;8(5):399-402.

54. Angelo RL. Controversies in arthroscopic shoulder surgery: arthroscopic versus open bankart repair, thermal treatment of capsular tissue, acromioplasties-are they necessary? Arthroscopy. 2003;19 Suppl 1: 224-228.

55. Meller R, Krettek C, Gosling T, Wahling K, Jagodzinski M, Zeichen J. Recurrent shoulder instability among athletes: changes in quality of life, sports activity, and muscle function following open repair. Knee Surg Sports Traumatol Arthrosc. 2007;15(3):295-304.
56. Arciero RA, Wheeler JH, Ryan JB, McBride JT. Arthroscopic Bankart repair versus nonoperative treatment for acute, initial anterior shoulder dislocations. Am J Sports Med. 1994;22(5):589-594.

57. Safran O, Milgrom C, Radeva-Petrova DR, Jaber S, Finestone A. Accuracy of the anterior apprehension test as a predictor of risk for redislocation after a first traumatic shoulder dislocation. Am J Sports Med. 2010;38(5):972-975.

58. Sachs RA, Lin D, Stone ML, Paxton E, Kuney M. Can the need for future surgery for acute traumatic anterior shoulder dislocation be predicted? J Bone Joint Surg Am. 2007;89(8):1665-1674.

59. Salomonsson B, von Heine A, Dahlborn M, et al. Bony Bankart is a positive predictive factor after primary shoulder dislocation. Knee Surg Sports Traumatol Arthrosc. 2010;18(10):1425-1431.

60. Kim DS, Yoon YS, Yi CH. Prevalence comparison of accompanying lesions between primary and recurrent anterior dislocation in the shoulder. Am J Sports Med. 2010;38(10):2071-2076.

61. Jakobsen BW, Johannsen HV, Suder P, Sojbjerg JO. Primary repair versus conservative treatment of first-time traumatic anterior dislocation of the shoulder: a randomized study with 10-year follow-up. Arthroscopy. 2007;23(2):118-123.
Open Access Journal of Sports Medicine

\section{Publish your work in this journal}

Open Access Journal of Sports Medicine is an international, peer-reviewed, open access journal publishing original research, reports, reviews and commentaries on all areas of sports medicine. The manuscript management system is completely online and includes a very quick and fair peer-review system.

\section{Dovepress}

Visit http://www.dovepress.com/testimonials.php to read real quotes from published authors. 